\title{
The Limited Inclusion of Children in Health and Health-related Policy
}

\author{
Mitch Blair, Michael Rigby, Arjun Menon, \\ Michael Mahgerefteh, Grit Kühne and Shalmali Deshpande
}

\begin{abstract}
Whilst nations have overall responsibility for policies to protect and serve their populations, in many countries, health policy and policies for children are delegated to regions or other local administrations, which make it a challenging subject to explore at a national level. We sought to establish which countries had specific strategies for child and adolescent health care, and whether primary care, social care and the school-healthcare interface was described and planned for, within any policies that exist. In addition, we established the extent to which a child health strategy and meaningful reference to children's records and care delivery exist in an e-health context. Of concern in the Models of Child Health Appraised (MOCHA) context is that $40 \%$ of European Union and European Economic Area countries had reported no health strategy for children, and more than a half had no reference to supporting delivery of children's health in their e-health strategy.

We investigated the differences in ownership and leadership of children's policy, which was a range of ministry input (health, education, labour, welfare or ministries of youth and family); as well as cross-ministerial involvement. In terms of national policy planning and provider planning, we investigated the level of discussion, consultation and interaction between national healthcare bodies (including insurance bodies), providers and the public in policy implementation. The MOCHA project scrutinised the way countries aim to harness the latest technologies by means of e-health strategies, to support health services for children, and found that some had no explicit plans whereas a few were implementing significant innovation. Given that children are a key sector of the population, who by very nature
\end{abstract}

(C) European Commission. Published by Emerald Publishing Limited. This chapter is published under the Creative Commons Attribution (CC BY 4.0) licence. Anyone may reproduce, distribute, translate and create derivative works of this chapter (for both commercial and non-commercial purposes), subject to full attribution to the original publication and authors. The full terms of this licence may be seen at http://creativecommons.org/licences/by/4.0/legalcode 
have a need to rely on government and formally governed services for their well-being in the years when they cannot themselves seek or advocate for services, our findings are particularly worrying.

Keywords: Health policy; children; adolescent; child primary care; e-health; strategy

\section{Introduction}

In trying to ascertain the details of child and adolescent health strategy across Europe, Models of Child Health Appraised (MOCHA) project researchers designed a questionnaire which was distributed to the 30 country agents, of which 27 responded. A challenge when undertaking this type of policy research is that in many countries (and not solely formally federated ones), many aspects of policy for operational services are delegated to regions or other local administrations; for instance, in France, Finland, Spain and the UK, there were reported issues with universal acceptance or adoption of plans when regional governments were involved. In this chapter, in all cases, replies are aggregated and analysed to the Member State level.

\section{The Existence of National Child and Adolescent Health Strategies}

The first aspect looked to ascertain whether countries have specific strategies for child and adolescent health care, whether these are included within other broader strategies, or simply do not exist at all. Countries were also asked details about the inclusion of primary health care, social care and the school-healthcare interface within their planning. Further to this, questions assessed the process of such planning, including key stakeholder involvement, the format of relevant discussions and when these take place.

Of the 27 countries responding, 17 country agents $(63 \%)$ responded that there was a specific strategy, while $10(37 \%)$ replied that their countries did not have one. Of the 17 countries with a specific child and adolescent health strategy, 16 $(94 \%)$ include primary healthcare planning for children within this, representing $59 \%$ of all countries surveyed. Only Norway does not have primary healthcare planning for children included within its specific child health strategy, although its standalone primary healthcare strategy accounts for children and adolescents. Thus, only half of European children live in a country which has a specific strategy for their health and health care.

Of the 10 countries that do not have a specific child and adolescent strategy, eight reported that they have primary healthcare planning included elsewhere. Malta and Hungary are the only two countries, out of all those who responded, that have neither primary healthcare planning nor specific child health strategies. 
Of the 27 respondents, $21(78 \%)$ reported that social planning is included in the planning of their strategies. However, different countries have different attitudes towards social care legislation with respect to child and adolescent health care. Five countries (Bulgaria, Denmark, France, Greece and Portugal) seem to focus on improving the lives of children with chronic health conditions and disabilities. Meanwhile, preventative healthcare services and health promotion are emphasised in seven countries (France, Germany, Greece, Iceland, Netherlands, Spain and the UK). Mental healthcare services are a primary aim of social care planning in six countries (Estonia, Greece, Italy, Latvia, Netherlands and the United Kingdom).

Of note, 10 countries (33\%) address equity issues specifically in their strategies. Reducing social inequality in health is the focus in four countries (Greece, Norway, Portugal and Romania). Meanwhile, there is a notable focus on protecting vulnerable groups of children in 6 countries (Czech Republic, Denmark, France, Romania, Spain and Greece).

\section{Ownership and Leadership of Children's Policies}

The Ministry of Health is involved in the strategic planning of child policy in 24 $(89 \%)$ countries, with the UK agent not responding to this question, while Slovenia and Malta claimed hardly any from the Ministry of Health. Further to this, the Ministry of Health assumed the clear lead ministerial role in strategy development for $17(63 \%)$ of the countries who responded. Other ministries that were also commonly quoted as being involved in the strategic planning were the Ministry of Education (14 countries), the Ministry of Labour (including Welfare and Social Affairs ministries) (12 countries) and the Ministry of or concerning Family (11 countries) - this includes countries who had ministries covering Youth, Children, Family and/or Sports.

Estonia and Germany had the largest amount of cross-ministerial involvement, with eight and six ministries involved respectively. In contrast, seven $(26 \%)$ countries reported single ministry involvement in the development of such strategies; these countries are Greece (Ministry of Health), Iceland (Ministry of Health), Lithuania (Ministry of Health), Malta (Ministry of Family, Social Solidarity and Children), Norway (Ministry of Health), Poland (Ministry of Health) and Romania (Ministry of Health). Of these countries, solely the respondent from Norway claimed that there is an open consultation process with key stakeholders before the ratification and implementation of a policy.

\section{Relationship between National Policy Planning and Provider Planning}

On the whole, countries generally described some level of discussion between national healthcare bodies and providers before the implementation of a strategy. In $20(74 \%)$ countries, healthcare professionals, scientific institutions or healthcare associations are described as being involved in the consultation process for strategy development. In France, Finland and Spain, it is seen that the implementation of national directives remains under the control of regional 
health authorities. In the UK meanwhile, the governments of each of the four 'Home Countries' (England, Northern Ireland, Scotland and Wales) are responsible for both the planning and the implementation of strategies within their respective 'countries'. This contrasts with Denmark, Netherlands and Norway, where national policies are developed and subsequently issued as directives to be followed by municipalities, with relevant guidance on directing and financing care at the local level.

Insurance bodies are involved in strategy discussions in a variety of countries, such as Bulgaria, Czech Republic and Lithuania. However, in Bulgaria and Czech Republic, it was found that there is government representation on the boards of the insurance companies. In Cyprus, the national health insurance fund will feature in strategy discussions once established in 2020. This is different to Hungary and Iceland where the national health insurance funds do not impact the content of the policies whatsoever, but are simply involved in the reimbursement process.

In several countries, draft legislation is created and then heavily discussed by key stakeholders before being passed on to parliament for approval. These countries include Bulgaria, Ireland, Latvia, Malta and Poland. In Croatia, the agent reported that it is difficult for interministerial strategic discussions to progress past initial stages, as there is 'no clearly defined institutional responsibility for each ministry involved'.

Public involvement in the development of child and adolescent health strategy seems to be low across Europe. Only in one part of one country, namely, Scotland within the UK, was it reported that young people are involved in policy discussions on child and adolescent health, through the Scottish Youth Parliament. The Austrian country agent made mention of the involvement of Patient Associations in the development of strategy.

\section{Issues in Health Policy Planning for Children's Services}

There appears to be no evident correlation between the date of accession to the European Union (EU) and the likelihood of having a strategy. For example, Germany and France, founding members of the EU, respectively, do and do not have a specific child and adolescent health strategy; similarly, Romania and Portugal, who both joined the EU at similar times, respectively, did and did not have a specific strategy either.

Cross-ministerial involvement heavily features in the development of child and adolescent healthcare strategies across Europe. Some country agents found that strategy planning for children engages a broad mix of ministries. Health ministries, while regularly involved, were not the only ministry needed for strategy planning. Education ministries were regularly cited for their involvement in the development of health education curricula, as well as for ensuring an appropriate interface between healthcare services and schools.

Estonia and Germany both described the largest cross-ministerial involvement in strategic planning. Interestingly, both these countries also benefit from 
broad stakeholder involvement in developing strategies, in keeping with their willingness for multi-organisational and multi-stakeholder input.

Universal adoption is also not guaranteed in countries where the powers of policy planning are devolved to regional governments. This goes to show that regardless of structure, federal countries can have difficulties in the planning and implementation of policy.

Even though key stakeholders were often involved in the consultation process for strategy development, youth involvement was a consistently lacking aspect of the strategy planning. However, an apparent exception to the lack of youth involvement in strategy or policy formation was the situation in Scotland, as described by the country agent from the UK. In this case, 'Members of the Children's Parliament and the Scottish Youth Parliament attended the 2017 [Scottish government] cabinet meeting. Issues raised included school and teachers, safety, bullying, children's rights, mental health and Europe'. This is the only cited clear example of very high-level engagement between youth and legislators in this area of questioning. Until now, The Scottish Youth Parliament has continued to be involved in contributing to the aspects of health strategy, with a further meeting with the Scottish government cabinet took place in 2018 (Scottish Youth Parliament, 2018).

Interestingly, in the 2017 meeting, Scottish Youth Parliament members requested a specific 'Young People's Mental Health Strategy' for 16-25-year-olds due to the 'transitional phase' in young people's lives at this stage.

\section{Identification of Children's Interests in e-Health Strategies}

Very much separate in many ways from the issue of health strategies is that of e-health strategies. Here, the focus is on how a government and health system will harness the very new technologies to support the health of its citizens and, in particular, how those new technologies will support healthcare delivery. And within this field, electronic health records (EHRs) and special functionalities within EHRs are major opportunity to ensure each child is looked after optimally (see Chapter 14). At the same time, because of their means of accessing health services, their need for advocacy in their early years and the special data sets and actions regarding children's health, special functionality and data items need to be provided for children in an e-health setting.

Given its central importance to future healthcare delivery, the MOCHA project had a specific focus on e-health, including assessing the degree of focus on children's interests within national e-health plans. One line of approach within this was to examine every country's e-health strategy and the degree of recognition this had of children's needs. This was included in a formal project (Kühne \& Rigby, 2016) and in a publication (Rigby et al, 2017).

In early 2016, the MOCHA country agents were asked about national e-health strategies, thus ensuring local analysis in national languages. Replies were received regarding 30 countries - of these 14 countries, that is Bulgaria, Cyprus, Denmark, France, Germany, Hungary, Ireland, Latvia, Lithuania, Norway, 


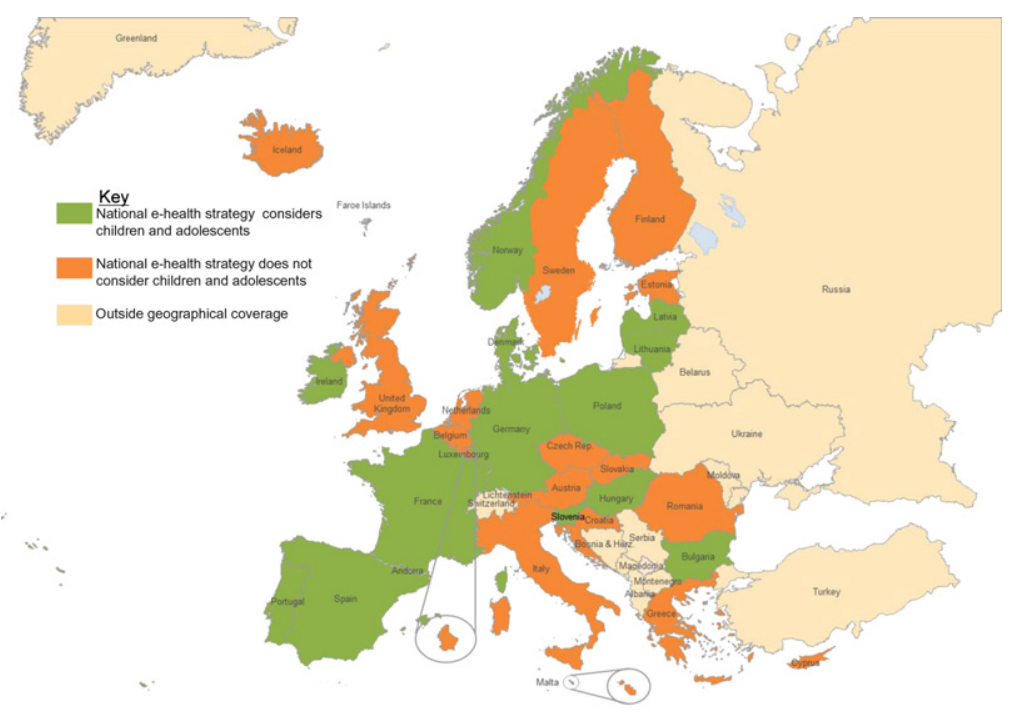

\section{을 Coth}

Figure 6.1. Overview on consideration of children and adolescents in national e-health strategies in Europe. Source: Map from FreeVectorMaps.com

Poland, Portugal, Slovenia and Spain, mentioned that their countries' e-health strategy contained considerations on children and adolescents. Sixteen countries replied that their national e-health strategy did not consider children and adolescents. The details as of that time are shown in a map in Figure 6.1.

Of the countries which did refer to children, a number of innovative initiatives were identified by countries which should have a very positive effect on health care and on individual children's health - for details see the cited deliverable and published chapter. This shows the contrast between the 16 out of 30 countries that had no specific mentions of children's healthcare and delivery needs in their e-health strategy and those countries that were focussing on specific innovation for the benefit of children.

\section{Summary}

In looking at Appraisal of Models of Child Health, two specific policy areas seemed worthy of specific study - existence of a children's health strategy and existence of meaningful reference to children's records and care delivery in an e-health context. Of concern in the MOCHA context is that $40 \%$ of EU and EEA countries had no health strategy for children, and more than a half had no reference to supporting delivery of children's health in their e-health strategy. The Czech Republic, Finland, Greece, Luxembourg, Malta and parts of the UK have reported neither health strategies for children nor children's health in their 
e-health strategy. Given that children are key sector of the population, who by very nature have a need to rely on government and formally governed services for their well-being in the years when they cannot themselves seek or advocate for services, this is particularly concerning.

\section{References}

Kühne, G., \& Rigby, M. (2016). Description and analysis of current child health electronic record keeping across Europe. Retrieved from http://www.childhealthservicemodels.eu/wp-content/uploads/2015/09/Description-and-analysis-ofcurrent-child-health-electronic-records.pdf

Rigby, M. J., Kühne, G., Majeed, A., \& Blair, M. E. (2017). Why are children's interests invisible in European National E-Health Strategies? In R. Randell, R. Cornet, C. McCowan, N. Peek, \& P. J. Scott (Eds.), Informatics for health: Connected citizen-led wellness and population health series studies in health technology and informatics (pp. 58-62, Vol. 235). iOS press e books.

Scottish Youth Parliament. (2018). Children and young people take part in second historic meeting with the Scottish Cabinet. Retrieved from https://www.syp.org.uk/children_ and_young_people_take_part_in_second_historic_meeting_with_the_scottish_cabinet 